\title{
AS MULHERES NA ÉCOLE NATIONALE SUPERIEURE DES BEAUX ARTS DE PARIS: OS REGULAMENTOS DE 1892 A 1937 E SUAS ALTERAÇÕES DECORRENTES DA PRESENÇA DAS ALUNAS-MULHERES
}

\author{
Fabiola Cristina Alves ${ }^{1}$ \\ lattes.cnpq.br/6838453885637422
}

\begin{abstract}
Resumo: Este artigo analisa os regulamentos da École Nationale Supérieure des Beaux-Arts de Paris, entre o período de 1892 a 1937, com o objetivo de discutir a inclusão da candidatura das mulheres para a formação nessa instituição. Apresenta as alterações adotadas nos usos dos ateliês para a recepção das alunas-mulheres e normativa específica para a permanência de alunas-mães.
\end{abstract}

Palavras-chave: Alunas-Mulheres; École Nationale Supérieure des Beaux-Arts; Regulamentos de 1892 a 1937.

\section{THE WOMEN AT THE ÉCOLE NATIONALE SUPERIEURE DES BEAUX ARTS DE PARIS: 1892 REGULATIONS TO 1937 AND ITS AMENDMENTS ARISING FROM THE PRESENCE OF THE STUDENTS - WOMEN}

\begin{abstract}
This article analyses the regulation of the Parisian École Nationale Supérieure des Beaux-Arts, between 1892 and 1937. Its objective is mapping women participation by the scope of their admission process, ateliers specific using rules and the normative for students that became mothers at this Parisian School of Art.
\end{abstract}

Keywords: students-women; École Nationale Supérieure des Beaux-Arts; regulation between 1892 and 1937.

\footnotetext{
${ }^{1}$ Doutora em Artes pela Universidade Estadual Paulista Júlio de Mesquita Filho (Brasil). Contato: biula alves@yahoo.com.br.
} 


\section{Considerações iniciais sobre a participação feminina na história e na arte}

A atuação das mulheres na história foi restrita por questões sociais, políticas ou culturais, a participação feminina estava invisível nas narrativas históricas desenvolvidas até pouco tempo. Por séculos, a história foi escrita sem quase citar mulheres como agentes do passado da humanidade, ou, pelo menos, a história escrita a partir de um modelo eurocêntrico, que se manteve por certo período como a leitura predominante sobre a humanidade e a sociedade no tempo.

Outras leituras desenvolvidas pela história, por sua vez chamada de história das minorias pelos adeptos ao modelo excludente da escrita em história, foram reveladas a nós após uma série de transformações sociais e de correntes intelectuais que nos ajudam ainda hoje a repensar e a significar a participação e a presença das mulheres na nossa história. Entre os estudos e as teorias que causaram um impacto nos modos de conceber e narrar a história, destacamos os estudos realizados por Simone de Beauvoir, sobretudo, no livro O segundo sexo publicado em 1949. Nessa obra, em oposição às teorias biológicas e deterministas, Beauvoir afirma que ser mulher é uma condição social e mostra-nos, ao longo dos capítulos, como as mulheres se tornam "mulheres" a partir de uma tradição sociocultural que as excluiu de certos espaços e determinou de modo limitador a atuação e a inserção das mulheres nas funções sociais vigentes até então no período pensado pela escritora.

Sobre a contribuição do pensamento de Beauvoir e o seu impacto político, Lucila Scavone, explica:

(...) resultou em sua célebre idéia de que não se nasce mulher, mas se torna mulher. Pode-se dizer que essa constatação lançou a primeira semente para os estudos de gênero, já que ela distingue o componente social do sexo feminino de seu aspecto biológico, ainda sem conceituar "gênero" (SCAVONE, 2008, p. 175).

No decorrer do século XX até hoje, observamos os avanços conquistados pelas mulheres no meio social e a progressão do conceito de 
"gênero", mesmo que em muitos países e culturas, tais direitos ainda se encontrem em processos de inicialização. O próprio movimento feminista, nas suas diversas versões, desde os anos de 1970 aos dias atuais, ganham, aos poucos, mais espaço nas discussões políticas. Neste estudo, nossa atenção é direcionada para as conquistas das mulheres no campo artístico, mas também político que envolve a formação institucional de artistas na França do final do século XIX e início do século XX. Mesmo antes das teorias de Simone de Beauvoir e das organizações feministas, as mulheres, aos poucos, adentravam aos espaços reservados e determinados socialmente para os homens de acordo com o modelo da visão europeia. Entre esses espaços proibidos às mulheres estava o campo da arte.

A história da arte, tendo em vista as características próprias de sua especialidade, mas também a sua origem inserida no modelo eurocêntrico de construção do discurso, mostra-nos da mesma forma que as mulheres foram excluídas dos processos sociais que permeiam o campo da produção artística. Embora as mulheres tenham sido representadas e muitas destas representações sejam relevantes para a compreensão da história individual e coletiva das nações, assim como para o saber específico sobre a arte, os modos de fazer arte, seus contextos e descobertas estilistas, notavelmente, a presença feminina foi condicionada, na sua maioria, como motivo ou modelo.

Observamos que, desde a antiguidade, são frequentes as representações do corpo feminino. Essas representações primeiramente foram ligadas a mitologia da fertilidade, mas também possuíam significados simbólicos produzidos no interior das culturas que produziram as representações dos corpos femininos. Os muitos sentidos, significados e símbolos construídos na antiguidade foram ao longo do tempo e do desenvolvimento das civilizações apropriados pelas culturas e contextos, sendo recriados e associados a outros valores, por vezes ligados ao tema do erótico e da sexualidade. A representação das mulheres nuas, dos corpos disponíveis para o olhar desejoso do homem, sobretudo na tradição da representação de "Vênus", é certamente um exemplo notável sobre a vinculação das mulheres como modelo ou motivo para que os artistas de- 
senvolvessem suas obras, contribuindo para a construção de um repertório imagético e para um memorial social coletivo que relacionasse os corpos femininos ao universo do erotismo e ao seu sexo. Sobre o assunto Stephanie Dahn Batista complementa:

O cânone da história da arte considerou, e em grande parte ainda mantém esse olhar, a representação do nu sob os critérios da sua origem, seu desenvolvimento e suas implicações simbólicas - alegóricas e até formais. É um possível acesso ao corpo que, entretanto, não problematiza seu significado histórico dentro de contextos socioculturais. Essa perspectiva também não produz conhecimento sobre a acepção e a função da nudez nos quadros da cultura e da sociedade, nem do erotismo considerando as diferenças das representações de feminilidade e masculinidade. Esses corpos sexuados em representação são lugares de negociações dentro de uma narrativa específica inscrita cujo fio condutor é, especialmente para o nu feminino, mas também para o masculino, o erotismo e o desejo. As imagens de masculinidade e feminilidade, como lugar de negociação cultural, materializam visualmente concepções de sexo, gênero e sexualidade vigentes dentro de um campo triangular entre imagem, olhar e gênero. Que corpo é produzido, por quem e para quem são perguntas cruciais que permeiam as relações de poder manifestadas pela imagem. (BATISTA, 2011, p. 26)

No entanto, se por um lado a representação das mulheres na história da arte desenvolveu-se a partir de estruturas simbólicas das sociedades, em destaque a europeia, tornando os corpos femininos alvo do desejo masculino e revelando visualmente as concepções sobre a condição feminina nas sociedades que as compreendiam mediadas por "jogos de poder" do olhar masculino sobre o sexo das mulheres representadas. Por outro lado, devemos ainda observar que outra forma de conceber a representação da figura feminina na história da arte se mostrou igualmente importante nas narrativas desenvolvidas por esta disciplina, a saber: a representação da mulher na sua condição de mãe. Neste caso, foi estabelecido a partir de uma tradição cristã um fortalecimento da representação da mulher-mãe pela simbologia que envolve a representação das Madonas, ou seja, a representação da figura de Maria mãe do menino Jesus.

Sem nos prolongar no assunto, é observável, ao longo da construção da iconografia cristã, o desenvolvimento simbólico de um repertório 
imagético comum que contribuiu significativamente para a compreensão da maternidade dentro de um escopo de pureza e santidade do período vivido pelas mulheres-mães. A representação de Maria em sua condição de mãe dedicada e celestial contribuiu significativamente para a construção de uma alegoria que se enraizou simbolicamente na memória coletiva. E há de se observar que entre as muitas cenas adotadas pelos artistas ao longo da história da arte para representar Maria em sua condição de mãe, uma, certamente, é emblemática: a representação da amamentação do menino Jesus. Uma tradição que se consolidou a partir da apropriação e da transformação simbólica da representação da deusa Ísis amamentando o herdeiro do trono egípcio à representação de Maria amamentando Jesus, herdeiro do trono celestial e salvador dos pecadores, segundo a tradição cristã. O que nos interessa nesse exemplo é, entre os muitos valores que são incorporados na representação da mulher que amamenta o seu filho, seja ela uma deusa pagã ou a Virgem Maria, o simbolismo da servidão materna ao seu filho que constituiu a condição da mulher-mãe. De acordo com Beauvoir:

O aleitamento é também uma servidão esgotante; um conjunto de fatores - o principal dos quais é, sem dúvida, o aparecimento de um hormônio, a progestina - traz às glândulas mamárias a secreção do leite; a ocorrência é dolorosa e acompanha-se, amiúde, de febres, e é em detrimento de seu próprio vigor que a mãe alimenta o recém-nascido. (BEAUVOIR, 1970, p. 50).

A representação da mulher que amamenta simboliza a mulher em estado de pureza, exercendo sua dedicação materna ao compartilhar sua energia e vitalidade com o filho indefeso. Porém, também revela a condição feminina de servidão à pequena criança pelo ato de alimentá-la, pela oferta das propriedades que o seu corpo pode ofertá-la. De acordo com o pensamento de Beauvoir, o aleitamento seria estabelecido pelas propriedades biológicas do sexo feminino, no entanto, ultrapassando os fatores biológicos da constituição da "fêmea", o aleitamento e sua função na relação mãe e filho foi construído socialmente como um momento de trocas emocionais e de carinho entre mãe e filho, mas também de servidão, uma vez que é função social da mãe se dedicar integralmente à criança duran- 
te o período de aleitamento, doando seu tempo exclusivamente a sua condição de ser mãe.

Obviamente, tal compreensão não condiz com a compreensão da maternidade na contemporaneidade. Atualmente, após a expansão das discussões de "gênero", das conquistas alcançadas pelas mulheres e pelo movimento feminista pós anos de 1970, temos outra compreensão e outros valores que são incorporados no ato de amamentar. No entanto, interessa-nos pontuar a compreensão da condição feminina a partir dos valores sociais que entendiam a condição de ser mãe como um exercício de servidão das mulheres aos seus filhos e, consequentemente, a sua família e ao seu marido. Pois, o valor e a função de servidão da mulher não se limitavam aos cuidados dedicados aos filhos, mas se desdobravam ao marido, a quem ela - a mulher - deveria também servir no espaço do lar, prezando pelos chamados "bons costumes", defendidos pela sociedade europeia no final do século XIX e início do século XX. Há de se observar que no interior dos sentidos atribuídos à condição da mulher nesse período, a condição de servidão se estrutura também nas bases da relação proprietário-propriedade, uma vez que as mulheres eram invisivelmente significadas na época citada como propriedades de seus maridos. Esses apontamentos são necessários, porque os documentos aqui estudados nos revelam como tais valores tornam-se visíveis nos Regulamentos de 1892 a 1937 da École Nationale Supérieure des Beaux-Arts de Paris.

Além disso, a atuação das mulheres como produtoras de arte, ou seja, artistas citadas pela narrativa produzida pela história da arte também é recente. Há leituras que se esforçam para encontrar os poucos "rastros" da existência das mulheres artistas antes do século XIX e XX. Se no período em que a arte era um ofício passado de mestre para discípulo, as mulheres não podiam assumir o lugar de discípula e muito menos de mestra, elas continuaram excluídas mesmo com a criação do modelo formal de ensino das artes plásticas: as chamadas Academias, muitas do século XVII. Este modelo excludente se manteve nas origens e nas regras normativas das escolas de educação formal criadas em diversos países. Com o intento de contribuir para o trabalho de reconstrução da lenta inserção das mulheres como produtoras, ou seja, elas mesmas na 
condição de artistas e não apenas modelo ou motivo para as obras desenvolvidas pelos artistas homens, que procuramos analisar os documentos preservados pelos Archives Nationales mantidos pelo governo francês. Destaca-se ainda que o trabalho de coleta de fontes primárias dos documentos aqui tratados foi desenvolvido durante o ano de 2015 com o financiamento da Coordenação de Aperfeiçoamento de Pessoal de Nível Superior (CAPES) em forma de bolsa de estudo e pesquisa.

\section{Analisando os Regulamentos de 1892 a 1937: questões de gênero}

Em consulta realizada nos Archives Nationales da França, foi possível mapear o início da inserção da presença feminina na École Nationale Supérieure des Beaux-Arts de Paris. Também foi possível observar as marcas do preconceito sofrido pelas jovens mulheres que enfrentaram a empreitada de estudar artes plásticas neste espaço formativo e que serão apresentadas ao longo da nossa reconstrução. Observamos e destacamos que no contexto do final do século XIX, a École Nationale Supérieure des Beaux-Arts era considerada a instituição de formação de jovens artistas mais conceituada no período em todo o território europeu. A referida instituição recebia estudantes de todas as localidades do território francês e europeu, recebendo consideravelmente jovens estudantes das belas-artes dos demais continentes, sendo que os estudantes estrangeiros, na sua maioria, passavam e se formavam na escola francesa com financiamento público dos países de suas origens. De dentro da École Nationale Supérieure des Beaux-Arts, os jovens artistas tinham contato com os ensinamentos dos artistas conceituados na época e eram preparados para os Salões oficiais promovidos pela instituição e por outras. Destacamos ainda que os salões foram, até as transformações ocorridas após movimentos da arte moderna, a principal e praticamente a única inserção efetiva dos jovens artistas no mercado de arte.

Foram analisados os regulamentos publicados pelo Ministère de l'Instruction Publique et Beaux-Arts do período de 1892 a 1937. Esses 
documentos, a nosso ver, revelam como o contexto francês do final do século XIX e início do século XX, oficializa a formação de mulheres para atuarem como artistas dentro dos espaços institucionalizados. Lembrando que, no mesmo período, o contexto francês foi campo de convívio entre o modo acadêmico de produção artística e os modos de fazer arte das chamadas vanguardas. Assim, ao longo da pesquisa com fontes primárias, percebemos a necessidade de dar visibilidade a esses documentos, pois os mesmos nos ajudam a melhor compreender a "batalha" assumida pelas primeiras alunas-mulheres na École Nationale Supérieure des Beaux-Arts e reconstituir os mecanismos legais que a sociedade e a política adotada na época pela referida instituição fizeram valer ou não o direito de acesso das mulheres no campo de formação e atuação do mundo das artes.

Neste intuito, foi na leitura dos regulamentos da École Nationale Supérieure des Beaux-Arts e pela observação de suas alterações anuais que notamos que em 1892 a presença de alunas-mulheres não era prevista no regulamento do respectivo ano. Abaixo o texto normativo das inscrições não cita o direito de candidatura para mulheres:

Art. 2. - Les jeunes gens qui veulent profiter de l'enseignement de l'école dovient préalablement se faire inscrire au secrétariat, justifier de leur âge et leur qualité, et, plus, s’ils sont étrangers, se présenter avec une lettre dintroction de l'ambassadeur, du ministre ou du consul général de leurs nation ${ }^{2}$.

O direito feminino à inscrição é afirmado no corpo do texto do regulamento apenas em 1898. Para definir ou explicar quem possuía o direito às inscrições, o texto original acrescenta uma explicação entre parênteses, que abaixo é observável.

2 AJ/52/438 - Archives Nationales (Pierrefitte-sur-Seine), documentos da École Nationale Supérieure des Beaux-Arts, Regulamento 1892.

"Art. 2. Os jovens que querem desfrutar do ensino da escola devem anteriormente registrar na secretaria, comprovante de idade e de qualidade, e, se eles são estrangeiros, apresentam-se com uma carta de apresentação do embaixador, o ministro ou o cônsul-geral de sua nação”. (Tradução nossa). 
Art. 2. - Les jeunes gens (hommes ou femmes) qui veulent profiter de l'enseignement de l'école dovient préalablement se faire inscrire au secrétariat, justifier de leur âge et leur qualité, et, plus, s'ils sont étrangers, se présenter avec une lettre d'introction de l'ambassadeur, du ministre ou du consul général de leurs nations.

O direito e a descrição sobre a possibilidade da candidatura de mulheres para a seleção da École Nationale Supérieure des Beaux-Arts foram observadas nos regulamentos posteriores de 1900, 1902, 1905, 1908, 1912, 1920, 1923 e nos regulamentos da década de 1930.

Um detalhe sobre a disposição dos ateliês da escola merece atenção, pois revelam os procedimentos adotados pela instituição para receber as alunas-mulheres. Sobre o assunto, o regulamento de 1892 descreve:

Art. 2. - Les atelier se divisent de la manière suivante : trois ateliers de peinture; trois ateliers de sculpture ; trois ateliers d'archicture ; un atelier de gravure en taille-douce ; un atelier de gravure en médaillhes et en pierre fines. 4

Observamos que o mesmo texto que descreve a disposição dos espaços dos ateliês usados pelos alunos em 1892 é mantido no regulamento de 1898, sendo este o mesmo regulamento em que aparece a inclusão do direito feminino de inscrição na escola. Já no regulamento de 1908, a disposição dos ateliês é descrita a partir de uma distinção de gênero declarada e oficializada.

Art. 2. - Les atelier se divisent de la manière suivante : quatre ateliers de peinture : trois pour les élèves-hommes, un pour le

3 AJ/52/438 - Archives Nationales (Pierrefitte-sur-Seine), documentos da École Nationale Supérieure des Beaux-Arts, Regulamento 1898.

"Art. 2. Os jovens (homens ou mulheres) que querem desfrutar do ensino da escola devem anteriormente registrar na secretaria, comprovante de idade e de qualidade, e, se eles são estrangeiros, apresentam-se com uma carta de apresentação do embaixador, o ministro ou o cônsul-geral de sua nação". (Tradução nossa).

4 AJ/52/438 - Archives Nationales (Pierrefitte-sur-Seine), documentos da École Nationale Supérieure des Beaux-Arts, Regulamento 1892.

"Art. 2. Os ateliês se dividem da maneira seguinte: três ateliês de pintura; três ateliês de escultura; três ateliês de arquitetura; um ateliê de gravura talha doce; um ateliê de gravura em medalhas e pedra fina." (Tradução nossa). 
élèves-femmes; quatre ateliers de sculpture: trois pour les élèves-hommes, un pour le élèves-femmes; trois ateliers d'archicture; un atelier de gravure en taille-douce ; un atelier de gravure en médaillhes et en pierre fines; un atelier de gravura à l'eau forte; un atelier de gravure sur bois; un atelier de lithografies.

Eram três ateliês para a prática de pintura e outros três para as aulas de escultura em 1892 e 1898, no entanto, após a inclusão das alunas-mulheres houve a criação de um ateliê de pintura e outro de escultura exclusivo para as aulas das alunas-mulheres, porém, a descrição da distinção de gênero dos ateliês é oficializada no regulamento posteriormente e não no momento da inclusão do direito feminino à inscrição na escola. Possivelmente, dois aspectos podem ter levado a criação dos ateliês destinados às mulheres: a) a prática das artes plásticas que, tanto para pintura quanto para escultura, de acordo com o modelo acadêmico de ensino da época, incluía prática da observação e do estudo do modelo nu, a participação das alunas-mulheres junto com os demais alunos-homens em um mesmo espaço de observação do corpo humano exposto em sua nudez, certamente, não era uma prática bem aceita na época. Além disso, a criação de espaços de sociabilidade específicos para as alunas-mulheres dentro da escola foram necessários para mantê-las incluídas parcialmente dentro dos processos de inserção dos futuros artistas no campo da arte; b) aparentemente há um crescimento dos espaços destinados para a prática artística; pois, se compararmos a quantidade total dos ateliês disponíveis em 1892 (que são 11) com o número de ateliês em 1908 (que são 16) podemos, pois, considerar que houve mais investimentos na abertura de novos ateliês, inclusive a criação de ateliês destinados para técnicas artísticas que anteriormente não eram oferecidas. Mesmo assim, a dis-

5 AJ/52/438 - Archives Nationales (Pierrefitte-sur-Seine), documentos da École Nationale Supérieure des Beaux-Arts, Regulamento 1908.

"Art. 2. Os ateliês se dividem da maneira seguinte: quatro ateliês de pintura, três para alunos-homens, um para alunas-mulheres; quatro ateliês de escultura; três para alunos-homens, um para alunas-mulheres; três ateliês de arquitetura; um ateliê de gravura talha doce; um ateliê de gravura em medalhas e pedra fina; um ateliê de gravura à água-forte; um ateliê de xilogravura; um ateliê de litografia." (Tradução nossa). 
tinção usada para a criação de ateliês para alunas-mulheres se baseia em padrões sociais estabelecidos pela sociedade europeia do período.

Esta leitura fica ainda mais evidente a partir do estudo do regulamento de 1935, vigente em todo o término da década de 1930 e que sofreu diversas alterações, ou seja, a inclusão de portarias. Observamos que para as inscrições o direito à candidatura é mantido para as mulheres.

Art. 2. Les jeunes gens (hommes ou femmes) désireux de devenir élèves libres ou élèves titulaires de l'école dovient préaláblement se faire inscrire au secrétariat. Aucun diplôme n'est exigé : les candidats sont tenus de remettre une demande écrite indiquant leurs date et lieu de naissance et leur qualité

Mais adiante o regulamento descreve a distinção por gênero existente dentro das práticas da instituição e também usada entre os procedimentos e critérios adotados.

Art. 25. Il est entendu qu'aucune distinction n'est faite entre les élèves-hommes et les élèves-femmes, soit au moment du jugement de l'épreuve de figure dessinée ou modelée d'après nature, soit lors du classement définitif. Chaque candidat garde le rang qui lui est assigné par le total de ses points7.

Conforme o texto acima, não havia distinção entre mulheres e homens nos processos avaliativos e na classificação final, sendo os candidatos classificados de acordo com a pontuação obtida. A respectiva normativa não existia nos regulamentos anteriores, a criação de um espaço no regulamento para o esclarecimento ou para uma declaração oficial so-

6 AJ/52/438 - Archives Nationales (Pierrefitte-sur-Seine), documentos da École Nationale Supérieure des Beaux-Arts, Regulamento 1935.

"Art. 2. Os jovens (homens ou mulheres) que desejam se tornar estudantes livres ou estudantes titulares da escola devem fazer a inscrição na secretaria. Nenhum diploma é exigido: os candidatos são obrigados apresentar um pedido por escrito indicando a sua data e o seu lugar de nascimento e sua qualidade." (Tradução nossa).

7 AJ/52/438 - Archives Nationales (Pierrefitte-sur-Seine), documentos da École Nationale Supérieure des Beaux-Arts, Regulamento 1935.

"Art. 25. Entende-se que não é feita qualquer distinção entre alunos-homens e alunas-mulheres, seja no momento do julgamento do teste de desenho de figura ou modelo da natureza, seja na classificação final. Cada candidato mantém a posição que lhe é atribuída pelo total de pontos.” (Tradução nossa) 
bre a "ausência" da distinção entre homens e mulheres nos exames, possivelmente, ocorreu porque as alunas-mulheres em algum momento se sentiram prejudicadas. Porém, a instituição preferiu oficializar a "ausência” de distinções de gênero nos exames, mesmo que a distinção ocorresse de forma subjetiva ou não pelas práticas dos examinadores.

No período estudado, os docentes eram homens e possuíam uma visibilidade valorizada pela sociedade da época, assim, podemos pensar no mesmo sentido de Pierre Bourdieu, que a distinção entre alunoshomens e alunas-mulheres era fruto da chamada dominação masculina. Sobre este conceito, Scavone explica:

[...] dominação masculina refere-se ao pressuposto da "incorporação" e da "aceitação" que os dominados (no caso, as mulheres) teriam para com os dominantes (no caso, os homens) pelo fato de terem internalizado em seus corpos os esquemas de dominação como Habitus, isto é, sistemas de disposições adquiridas que internalizam as estruturas sociais. (SCAVONE, 2008, p. 182).

Tendo em mente, o Art. 25 do Regulamento de 1935 esclarece o assunto de uma possível distinção de gênero vigente nas práticas dos examinadores, entendemos que as alunas-mulheres, em minoria e em recente inserção no espaço da formação artística, estariam submetidas a um sistema que as colocavam em constante condição de dominadas, deste modo, mesmo que prejudicadas, o sistema encontrava modos de legitimar ainda mais a relação da dominação masculina, uma vez que a "fala" feminina era invisível em comparação a "fala" dos docentes.

Quanto aos ateliês, o regulamento de 1935 descreve:

Art. 6. Les ateliers de l'École Nationale Supérieure des BeauxArts se divisent de la manière suivante :

Quatre ateliers de peinture, dont un est exclusivement réservé aux élèves femmes.

Quatre ateliers de sculpture, dont un est excluivement réservé aux élèves femmes.

Trois atelier d'archicture.

Un atelier de gravure un taille-douce et à l'eau-forte.

Un atelier de gravure sur bois.

Un atelier de lithografie. 
Un atelier de fresque pours les élèves de la section de peinture : quelques élèves sculpteurs et archictes peuvent être autorisés à y travailler; ils doivent être présentés pour leur chef d'atelier et acceptés pour le professeur de fresque.

Un atelier de sculpture pratique destiné à familiariser les élèves de la section de sculpture avec le travail de la pierre, du marbre et $d u$ bois. Quelques élèves peintres et archictes peuvent être autorisés à y travailler ; ils doivent être présentés pour leur chef d'atelier et acceptés pour le professeur de sculpture pratique ${ }^{8}$.

Notamos que durante a década de 1930, a presença das alunasmulheres ainda é estabelecida a partir da sua separação nos ateliês específicos de pintura e de escultura. Novas normativas para a prática da pintura de afresco e da escultura são apresentadas nos dois últimos parágrafos, descrevendo distinções para o uso dos ateliês de acordo com a inscrição do aluno na formação de pintura ou escultura ou arquitetura, mas não por gênero.

A presença feminina na École Nationale Supérieure des BeauxArts demandou à instituição, como já constatamos, a necessidade de normativas específicas para o tratamento oferecido às alunas-mulheres, como a criação de ateliês exclusivos, ou seja, um espaço de sociabilidade reservado para a interação entre as alunas, o docente e o modelo. Intera-

8 AJ/52/438 - Archives Nationales (Pierrefitte-sur-Seine), documentos da École Nationale Supérieure des Beaux-Arts, Regulamento 1935.

"Art.6. Os ateliês da Escola Nacional de Belas Artes se dividem da seguinte maneira:

Quatro ateliês de pintura, um dos quais é exclusivamente reservado às alunasmulheres.

Quatro ateliês de escultura, um dos quais é exclusivamente reservado às alunasmulheres.

Três ateliês de arquitetura.

Um ateliê de gravura em talhe doce e de água-forte.

Um ateliê de xilogravura.

Um ateliê de litografia.

Um ateliê de afresco para os alunos da seção de pintura: alguns alunos escultores e arquitetos podem ser autorizados à lá trabalhar; eles devem ser apresentados ao chefe do ateliê e aceitos pelo professor de afresco.

Um ateliê de escultura prática destinado a familiarizar os alunos da seção de escultura com o trabalho em pedra, mármore e madeira. Alguns alunos pintores e arquitetos podem ser autorizados à lá trabalhar; eles devem ser apresentados ao chefe do ateliê e aceitos pelo professor de escultura." (Tradução nossa). 
ção que deveria ser diferente dos alunos-homens no mesmo período. A distinção entre os espaços seria um tipo de classificação social da época e adotada pela comunidade da escola. Neste sentido, acrescentamos a esta leitura as palavras de Bourdieu:

[...] os indivíduos reunidos em uma classe construída a partir de uma relação particular, apesar de ser particularmente determinante, trazem sempre com eles, além das propriedades pertinentes que se encontram na origem de sua classificação, algumas propriedades secundárias que, deste modo, são introduzidas clandestinamente no modelo explicativo. O mesmo é dizer que uma classe ou uma fração de classe é definida não só por sua posição nas relações de produção, tal como ela pode ser identificada através de índices - por exemplo, profissões, renda ou, até mesmo, níveis de instrução -, mas também pela proporção entre número de homens e o de mulheres, correspondente a determinada distribuição no espaço geográfico (que, do ponto de vista social, nunca é neutra), e por um conjunto de características auxiliares que, a título de exigências tácitas, podem funcionar como princípios reais de seleção ou exclusão sem nunca serem formalmente enunciados - esse é o caso, por exemplo, da filiação ou do gênero; com efeito, inúmeros critérios oficiais servem de máscara a critérios dissimulados [...] (BOURDIEU, 2007, p. 97-8).

A delimitação do espaço de acesso aos ateliês, lugar de interação e de sociabilidade entre os indivíduos da comunidade da École Nationale Supérieure des Beaux-Arts durante o início do século XX, revela que embora tenha sido significativa a mudança de valores sociais como foi a inserção de alunas-mulheres na escola, ainda assim, persistiam com força os valores da dominação masculina como padrão determinante. Por consequência, o espaço dos ateliês reservados às alunas-mulheres poderia determinar a quantidade de alunas que seriam aceitas na seleção de candidaturas uma vez que o espaço da escola comportava um número superior de alunos-homens, pois os ateliês masculinos eram ofertados em maior quantidade.

Além das adaptações já citadas que foram realizadas pela École Nationale Supérieure des Beaux-Arts para receber as alunas-mulheres desde 1898, seja nos espaços para os exercícios das práticas artísticas ou 
no seu regulamento, uma delas, em especial, merece nossa atenção final: a portaria de 27 de fevereiro de 1937.

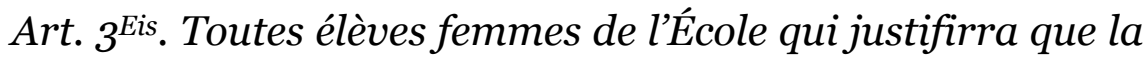
naissancee d'un enfant l'aura impéchée da participar à deux ou plusireurs concours ou examany au cours d'une année scolaire aura droit à six mois de prolongation de la durée de ses éteny à l' École Nationale et Spéciale des Beaux-Arts, sans que cette prolongation puisse dépasser toutfois la limite fixée pour les élèves ayant accomplileurs sarvia militaire ${ }^{9}$.

No documento consultado junto ao Archives Nationales, o Art. $3^{\text {Eis }}$ acima citado foi incluído na publicação original do regulamento de 1935, em papel à parte, colado no caderno do regulamento, o texto é apresentado em manuscrito. A transcrição foi feita conforme o documento preservado. Observamos que o Art. $3^{\text {Eis }}$ oferece às alunas-mulheres que tiveram filhos ao longo do período de formação o prolongamento de mais seis meses no tempo de conclusão dos estudos, algo parecido com a atual "licença maternidade". Entretanto, a portaria de 1937 também oficializa a exclusão das alunas-mulheres de sua inserção no campo artístico oficial quando proíbe às jovens mães de participarem dos concursos e salões oferecidos pelo Estado Francês. Os Salões promovidos eram o meio mais importante de inserção dos jovens artistas no campo de arte, sobretudo, o mercado de arte oficial. Os Salões do respectivo período estudado neste artigo também ofereciam o acesso aos prêmios e ao financiamento dos estudos dos premiados. Raramente as mulheres ganhavam visibilidade nos salões promovidos, porém, o direito à participação das alunasmulheres era garantido, com exceção das alunas-mães após a portaria de 1937 que oficializa a sua exclusão total como uma medida punitiva à ma-

$9 \mathrm{AJ} / 52 / 438$ - Archives Nationales (Pierrefitte-sur-Seine), documentos da École Nationale Supérieure des Beaux-Arts.

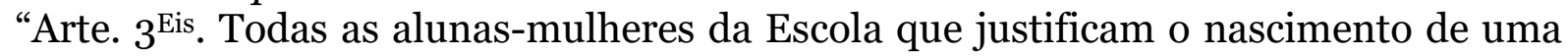
criança será impedida de participar de dois ou mais concursos ou exames em curso do ano escolar tendo o direito a seis meses de prolongamento da duração de sua estadia na Escola Nacional de Belas Artes, sem que esta prolongação ultrapasse o limite fixado para os alunos que cumprem serviço militar". (Tradução nossa). 
ternidade ou ao significado de "servidão" da mãe à família que foi constituído socialmente como sentido atribuído às mulheres em condição de ser mãe. Nesta concepção, a mulher-mãe dedicaria seu tempo à criança na esfera da vida particular, sendo progressivamente excluída de outros processos de inserção da vida pública como era o espaço do universo artístico.

A maternidade, neste contexto, a nosso ver, significava a progressiva exclusão da participação das futuras mulheres artistas no mercado da arte francesa do início do século XX. Perante uma sociedade, ainda inicializando a inserção feminina em espaços sociais para além do espaço doméstico, a maternidade exprimia a possibilidade de legitimar a supressão da presença feminina no campo da arte. A novidade que foi a possibilidade de formação oficial de artistas mulheres, pouco quista pelos valores conservadores da época, mascarava pelo Art. $3^{\text {Eis }}$ de 1937 a compreensão de um sentido opressor sobre a maternidade, que só foi discutido, na segunda metade do século XX, após o pensamento de Beauvoir.

A maternidade começava, então, a ser compreendida como uma construção social, que designava o lugar das mulheres na família e na sociedade, isto é, a causa principal da dominação do sexo masculino sobre o sexo feminino (SCAVONE, 2001, 138).

Em um contexto de dominação masculina como foi o início do século XX, dentro de um espaço institucionalizado pelos valores desta dominação como foi a École Nationale Supérieure des Beaux-Arts, fica claro que a possibilidade da maternidade das alunas-mulheres não era um fator de impedimento da conclusão dos estudos, já que até foram acrescentados seis meses de prolongamento no tempo total de formação das alunas-mães, porém, era um fator legítimo para a sociedade determinar a exclusão total das futuras artistas-mães do mercado de arte oficial, pois ao gerar um filho as alunas-mulheres são recolocadas no lugar de inviabilidade construído socialmente. 


\section{Considerações finais}

A análise dos regulamentos de 1892 a 1937 revelam, certamente, a conquista feminina dentro do espaço oficial de formação artística da França do início do século XX, porém, é visível que o direito feminino à inscrição, na École Nationale Supérieure des Beaux-Arts, foi concedido parcialmente, pois a instituição, preservando os valores sociais vigentes do contexto, procurou encontrar meios de adaptar a presença feminina dentro do espaço da escola, assim como de puni-las ou excluí-las oficialmente quando possível. $\mathrm{O}$ direito feminino à inscrição na escola, embora garantido, não significou a garantia dos direitos igualitários na sociedade da "liberté, égalité, fraternité".

Observamos ainda que os valores sociais que significavam a condição da maternidade como um exercício de servidão da mulher à criança e à família mostrou-se parte das estruturas invisíveis que operaram no período vivenciado pelas primeiras alunas-mulheres na École Nationale Supérieure des Beaux-Arts, pois, a recente empreitada das mulheres artistas no universo das artes não concebeu com facilidade a possibilidade de uma artista mulher dividir o seu tempo entre a "servidão" materna e o fazer artístico. O artista, o pintor, o escultor e o arquiteto na época eram profissões com inserção no mercado de arte promovido e, por vezes, vinculado às obras do Estado, assim para se tornar um artista aceito nos Salões e contratado pelo Estado era necessário tempo para dedicação integral, algo que a mulher-mãe não poderia oferecer de acordo com as estruturas sociais da época. Além disso, o pouco acesso de mulheres à École Nationale Supérieure des Beaux-Arts, considerando o menor número de alunas e de espaço físico disponível dentro da escola para atendê-las, é por nós entendida como uma forma de manutenção das estruturas opressoras da sociedade machista da época, mas que também contribuiu no período para a reafirmação da negação de um espaço profissional reservado às mulheres no mercado de trabalho. 


\section{Referências}

BATISTA, S. D. O corpo falante: as inscrições discursivas do corpo na pintura acadêmica brasileira do século XIX. Tese (doutorado em História), Setor de História da Universidade Federal do Paraná, 2011.

BEAUVOIR, Simone de. O segundo Sexo. Trad. Sérgio Milliet. São Paulo: Difusão Européia do Livro, 1970.

BOURDIEU, Pierre. A distinção: crítica social do julgamento. Trad. Daniela Kern; Guilherme J. F. Teixeira. São Paulo: Edusp; Porto Alegre, RS: Zouk, 2007.

SCAVONE, Lucila. A maternidade e o feminismo: diálogo com as ciências sociais. In: Cadernos Pagu, Campinas, n. 16, 2001.

. Estudos de gênero: uma sociologia feminista? In: Estudos Feministas, Florianópolis, n. 16, v. 1, jan./abril 2008.

\section{Fontes}

AJ/52/438 - Archives Nationales (Pierrefitte-sur-Seine), documentos da École Nationale Supérieure des Beaux-Arts.

Recebido em 10 de agosto de 2016. Aprovado em 02 de setembro de 2016. 